
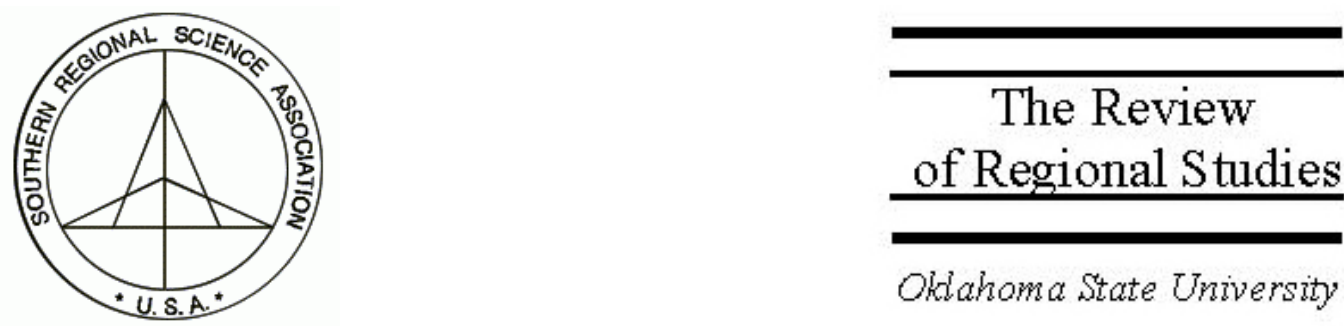

Oklahoma State University

\title{
Lake Rehabilitation and the Value of Shoreline Real Estate: Evidence from Delavan, Wisconsin
}

\author{
Russ Kashian \\ Department of Economics, University of Wisconsin-Whitewater, \\ 800 West Main Street, Whitewater, Wisconsin 53190,e-mail: kashianr@uww.edu \\ Mark E. Eiswerth \\ Department of Economics, University of Wisconsin-Whitewater, 800 West Main Street, \\ Whitewater, Wisconsin 53190,e-mail:eiswertm@uww.edu \\ Mark Skidmore \\ Department of Economics, University of Wisconsin-Whitewater, \\ 800 West Main Street, Whitewater, Wisconsin 53190, \\ e-mail:skidmorm@uww.edu
}

\begin{abstract}
In this article we use the hedonic price model to estimate the effect of a change in water quality on the value of real estate in the lake community of Delavan, Wisconsin. Hedonic techniques show that a $\$ 7$ million rehabilitation program significantly increased Delavan Lake shoreline property values. Existing research demonstrates that the use of objective water quality measures (as opposed to subjective measures) is important for estimating the implicit value of water quality in hedonic analyses. This article provides new evidence on the economic benefits of clean water by measuring the change in property values attributed to an observable rehabilitation event.
\end{abstract}

Keywords: Hedonic analysis; Lake rehabilitation; Regional economic development

JEL classification: H43; Q25; Q51

The authors would like to thank the Delavan Lake Improvement Association and the Delavan Lake Sanitary District for assistance and David Clark for helpful comments. The study was funded by a grant from the University of Wisconsin-Extension. 


\section{INTRODUCTION}

In the early 1980s, Delavan Lake (located in Walworth County in southeastern Wisconsin) experienced significant water quality problems, including nutrification and resultant algal blooms, reduced water clarity, and an overall eutrophic state. Scientific studies indicated that non-point sources of nutrients such as phosphorus were contributing to these water quality problems. In response, agencies at multiple levels of government undertook an expansive, intensive, and historically unique $\$ 7$ million lake rehabilitation program between 1989 and 1993. This rehabilitation included the actual draining of Delavan Lake and a number of steps to eliminate undesirable fish species, algae, and nutrients that were contributing to the eutrophication problem. Once these actions were taken, the lake basin was allowed to refill and game fish were restocked. The rehabilitation effort created a substantial improvement in the environmental quality of Delavan Lake, as well as associated benefits such as a dramatic improvement in the quality of its recreational fishery. Due to the uncommon magnitude of this rehabilitation effort as well as the extensive documentation of the lakes' environmental history, this otherwise relatively obscure lake has become quite well known in national and even international scientific circles.

An important but to date unanswered economic question begged by a retrospective view of the lake's rehabilitation is as follows: What economic benefits accrued as a result of the $\$ 7$ million investment in the lake's quality? This article focuses solely on the enhanced property values that are hypothesized to have resulted from the rehabilitation and uses hedonic analysis to estimate those incremental values. ${ }^{1}$ In order to conduct this analysis, information on property values and housing characteristics was collected for numerous residential properties on and near three lakes in Walworth County, Wisconsin. These lakes, all drainage lakes, are similar in location within Walworth County. They are also similar in terms of depth, with the deepest parts of each lake ranging from 44 to 58 feet. Since drainage lakes are fed primarily by streams and with outlets into streams or rivers, they are particularly vulnerable to surface runoff problems. Also included in the analysis are homes in the non-lake Walworth County community of Darien, Wisconsin.

While the literature on many environmental goods (such as clean air) is rich, the existing research using the hedonic method to determine the value of water quality is more limited. We add to the existing literature by estimating the effects of an unusual human-induced restoration event, with concomitant enhancements to water clarity, on property values. One barrier in previous research is the limited availability of a water quality measure for the average consumer: water pollutants are often microscopic and thus unobservable. It is only when the concentrations are egregious that they are noticed by homeowners. Also, previous research may have been hampered by a difference between perceived water quality and reality (Poor et al. 2001). The well-publicized lake

${ }^{1}$ The estimation of other categories of benefits resulting from the Delavan Lake cleanup (e.g., increased economic activity at the regional level) is discussed in Eiswerth, Kashian, and Skidmore (2005). 
restoration project conducted on Delavan Lake in southeastern Wisconsin offers a unique opportunity to estimate the effect of a substantial change in water quality on lakefront property values. Specifically, we use hedonic techniques to evaluate the determinants of variation in property values over time and across homes in a heterogeneous and wellintegrated housing market with the objective of isolating the effect of a change in lake water quality on the value of such properties. By using properties located on several similar yet unique lakes, we attempt to evaluate the impact that the restoration project produced.

Our study is conditioned by virtue of two fortunate occurrences. First, the occurrence of the lake rehabilitation event provides a rare opportunity to assess the impact of a very large (i.e., not marginal) improvement in water quality. Second, there are good historical records of a key water quality attribute (water clarity) at each of the three lake areas included in our hedonic analysis. We are therefore able to cast our study in two dimensions. The first involves an "event history" modeling approach in which we estimate the impact of the rehabilitation. This approach allows us to estimate: a) the value that accrues to a property simply as a result of having lakefront (versus not having lakefront) at a particular lake at different points in time; and b) the incremental value of lakefront per linear foot of shoreline at different points in time. Our second approach involves a more traditional framework of including a water quality measure in a hedonic framework in order to value changes in the environmental attribute. At the same time, we also control for time- and community-specific effects that may be partially correlated with, but are distinct from, the change in water clarity. This latter approach allows for the estimation of the incremental value of residential lakeshore properties per foot of enhanced lake water clarity.

\section{LITERATURE REVIEW}

A given housing unit is best characterized as consisting of a bundle of attributes that in sum describe the structure itself, the land upon which it is built, and the relevant locational characteristics. Much of the previous research that examines housing markets has used the hedonic framework. The hedonic approach can separate the internal property attributes (baths, bedrooms, square feet, etc.) from the public and private good attributes associated with location. In the case of shoreline, proximity and access to water and water-related open space as well as views and other amenities are provided to the property owner.

Previous research regarding the relationship between housing value and waterfront views overlaps several academic fields. Darling (1973) investigated the influence of distance from lake parks on property value. In this early study, the coefficient was negative and significant, indicating that a closer proximity to lake parks increased property values. Brown and Pollakowski (1977) confirmed that distance from the waterfront reduces selling prices. Plattner and Campbell (1978) found that the view of ponds or small lakes increased the value of condominiums in Massachusetts. Seiler, Bond, and Seiler's (2001) 
research on Lake Erie verified a significant and positive relationship between a view of Lake Erie and property value.

Since the aforementioned articles did not focus on quality, it is helpful to move from this initial establishment of relationship between waterfront view and property value to consider the related issue of water quality. David's (1968) hedonic study examined the correlation between lakeshore property values on artificial lakes in Wisconsin and water quality. Although the measure of water quality was correlated with property prices, the subjective measure of water "quality" was a limitation of this initial research. Epp and Al-Ani (1979) also tested the relationship between changes in water quality and house values. This work provided support for pro-active efforts in water quality protection/ improvement. A key conclusion of this work was that the price of properties adjacent to good water quality are sensitive to changes in water quality, but marginal improvement in areas of poor water quality offer no benefit in property valuations.

Young and Teti (1984) examined a case in which the water quality around St. Albans Bay in northern Vermont was degraded. This research concluded that property values around St. Albans Bay suffered relative to the properties outside the bay. Brashares (1985) used an approach similar to that of David (1968) to examine the effect of water quality on Lake Michigan on property valuation, except that it improved upon David's research by including 39 specific objective measures of Lake Michigan water quality. Brashares found that observable water quality measures were capitalized into the price of lakefront real estate.

The work of Steinnes (1992) examined the importance of human perception by examining the relationship between a perception of poor quality and property values. Steinnes found that the presence of tannic acid, which gives the water a dark brown color, negatively affects property values. Note, however, that while tannic acid discolors water it has no true negative effects on water quality in terms of environmental degradation. Mendelsohn et al. (1992), however, showed that true diminished water quality does not affect property values until awareness is elevated. In a survey of 500 property owners on 34 Maine lakes, Boyle et al. (1998) determined that water quality issues influenced the purchase decision for potential property owners. Using the alternate technique of willingness to pay (WTP), Boyle et al. (1998) determined that there was a willingness to pay for improved water quality. This WTP represented an economic demand for water quality by lakeshore property owners.

Michael, Boyle, and Bouchard (2000) revisited the issue of perceived water quality and valuation. Within a hedonic pricing model, their water quality variables significantly affected housing prices. Finally, readily available water quality measures had a significant effect on property values along the Chesapeake Bay (Legget and Bockstael 2000). This body of research demonstrated that the use of objective water quality measures (as opposed to subjective measures) is important for estimating the implicit value of water quality in hedonic modeling (Poor et al. 2001). In addition, this body of work suggests that awareness of water quality issues is also important. In summary, these studies show 
that water quality can significantly affect property prices. At the same time, water quality measures that are not perceivable to the general public, although important, may not be capitalized into property values.

While this previous work represents a body of knowledge regarding the relationship between water quality and property values, a limitation is that this research has primarily relied on cross-sectional data. Thus, the existing research does not offer insight into how changing water quality translates into changing property values. We add to the literature by utilizing changes in water quality over time to estimate any effects on property values. Such a study is made possible by the unusual restoration project implemented to reverse the drastic decline in quality at Delavan Lake.

\section{DATA}

The present study compiles data on assessed valuation of residential property and characteristics for 1987, 1995, and 2003 from three lake districts and one non-lake district in Walworth County, Wisconsin. The choice to use assessed value data (as opposed to actual sales price data) is related to three issues. First, due to the dearth of sales in the lake communities for the years we examine, sales price data is limited and nonrandom. For example, in 2003 on Lake Beulah, there were only six homes sold with sales prices ranging from $\$ 145,000$ to $\$ 2.5$ million. Second, we note that other researchers such as Steinnes (1992) have utilized assessed value data to evaluate water quality issues. Birch and Sunderman (2003) argued that sales price data is not appropriate for small areas due to the small number of resales during a given period of time. Pollakowski (1995) cited several structural problems in transactions data. Among the difficulties are: the inclusion of non-arms length transactions where prices are significantly lower than market due to a relationship between buyer and seller and reporting errors caused by seller financing. In addition, Clapp and Giaccotto (1992) argued that the political climate discourages systematic error in the valuation of property and that property valuation is regularly updated to reflect current market prices by a number of institutional mechanisms. In Wisconsin assessed valuation must be updated on a regular basis and in fact is required by state law whenever average assessed values fall below 90 percent of full market value. ${ }^{2}$ For these reasons, assessed valuations are used in the present study.

In this region property values, especially lake property values, are influenced by the Chicago market. Walworth County is just a two-hour drive from the Chicagoland and thus serves as a recreational area for many Chicago residents. The properties were randomly chosen from all homes located in the Delavan Lake, Lake Beulah, and Lauderdale Lakes areas as well as the town of Darien. Delavan Lake is located in the town of

\footnotetext{
${ }^{2}$ All properties were reassessed at least once during the 1987-2003 period: Delavan properties were reassessed in 1992 and 2000; Darien properties were reassessed in 2003; Lauderdale Lakes properties were reassessed in 2000; and Lake Beulah properties were reassessed in 1995 and 2001. Given that all properties were reassessed at least once, it seems unlikely that our results are affected by the timing of the reassessments. Further, the values used are in fact estimates of market values, which are adjusted annually to reflect local housing market conditions.
} 
Delavan, Lake Beulah is located in the town of East Troy, and properties on the Lauderdale Lakes are located in the Town of Lagrange. The properties from the Town of Darien provide a comparison real estate market without lakefront. ${ }^{3}$ A number of explanatory variables are included in the hedonic regressions to capture the factors that are typically found to influence residential property assessed values.

Data on residential assessed valuation and characteristics come from several sources. The land and improvement valuations for 2003 are provided by Walworth County. Lakefront is provided through Walworth County plat maps. The individual townships provided the land and improvement valuations for 1987 and $1995 .{ }^{4}$ The various town assessors provided data on the housing characteristics used in the hedonic equations. Only residential properties as opposed to commercial properties are included in the data set. Lastly, only those properties with dwellings in 1987 are included, and properties with significant structural additions over the period of analysis are omitted.

In addition to a series of variables that characterize the properties, time indicator variables are included for 1995 and 2003 to control for the average increase in all properties over time. These data provide the basis for analyzing the effect of the Delavan Lake restoration project that occurred between 1989 and 1993 on the value of lake property relative to comparative properties on other nearby lakes. The dataset consists of characteristics of 314 homes at three different points in time yielding a total of 942 observations. ${ }^{5}$ Before turning to the regression results, consider Figure 1, which shows that relative to Beulah and Lauderdale lakefront properties, Delavan values appear to have appreciated at a faster pace, particularly between 1987 and 1995 - the period during which lake restoration took place.

\section{HEDONIC MODELS}

\subsection{General Approach}

Our use of hedonic pricing follows the lead of Rosen (1974), who shows that the price of a good is a function of the bundle of characteristics embodied in the good. The final price of a good depends on the quality of a number of specific attributes. In the context of a house, each homeowner receives a different benefit (utility) from a given residential property. In this framework utility, $U$ is a function of a composite good, $X$, the home, $H$, and taste parameters, $T$. Thus, $U_{i}=U_{i}\left(X_{i}, H_{i}, T_{i}\right)$ for individual $i$. Utility is maximized according to a budget constraint, $P^{*} X+P_{H}{ }^{*} H=M$, where $P$ is the price of all other goods, $P_{H}$ is the price of a home, and $M$ is income. Constrained optimization yields

\footnotetext{
${ }^{3}$ Darien is not located on or near a lake. However, residents may enjoy nearby lakes via public access points. All three lakes have public access points.

${ }^{4}$ Due to a large number of missing variables, assessment data for 1994 is used for the Delavan properties. However, in reviewing the assessment rolls from 1993, 1994, and 1996, this was a midpoint assessment period and thus does not affect assessed valuation.

${ }^{5}$ Depending on the regression, the total number of observations employed may be reduced due to missing data.
} 


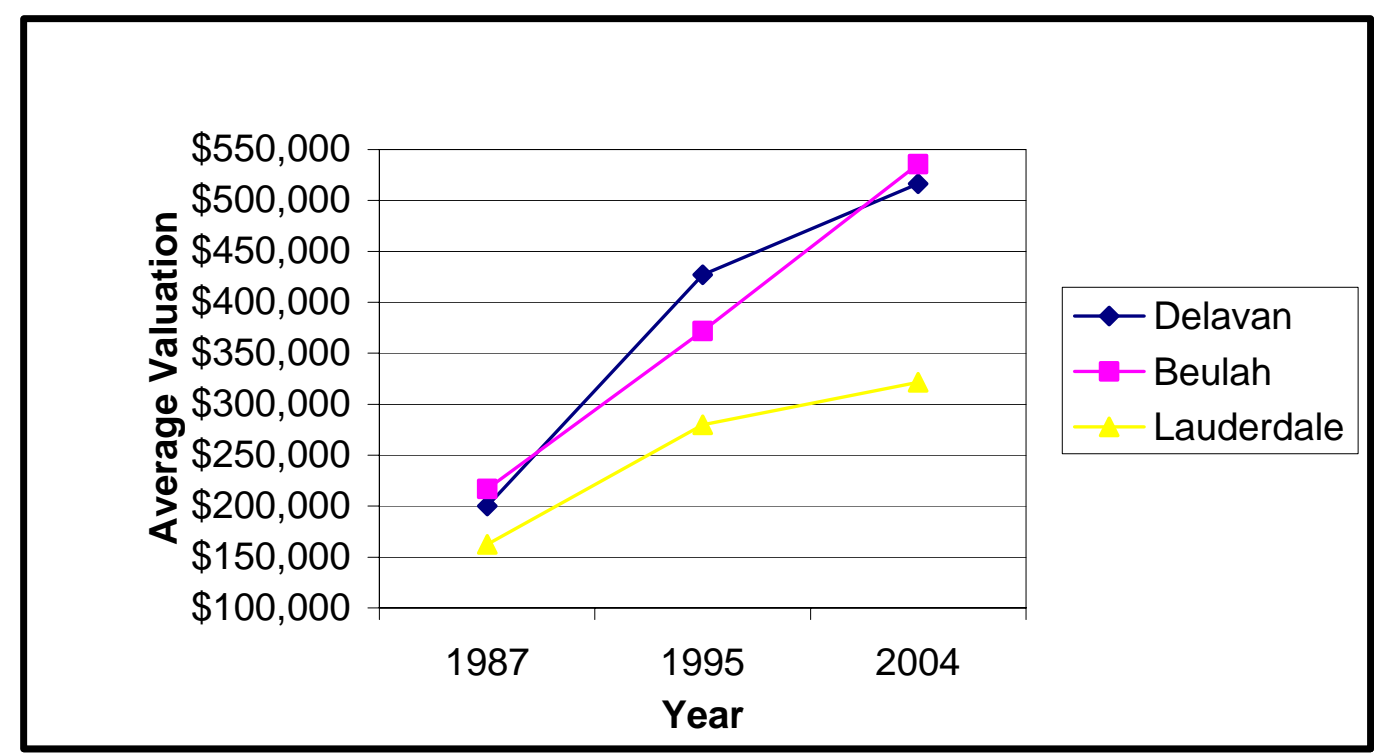

FIGURE 1. Average Lake Property Values

a set of demand functions where $H_{i}=H_{i}\left(P, P_{H}, T_{i}, M\right)$. Each homeowner has a collection of indifference curves representing his or her tradeoff between the different amounts of amenities and services embodied in a given home and how much he or she is willing to pay for them. Each residential property therefore offers varying characteristics that may satisfy a homeowner.

In the context of the present study, the dependent variable is the assessed value (land plus improvements) of a residential property. We postulate that property values are in part determined by: 1) the presence/absence of lakefront; 2) the number of feet of lakefront that a property has; and 3) the water quality of the lake in question. We are particularly interested in whether the restoration project on Delavan Lake, which occurred between 1987 and 1995, caused an increase in the value of Delavan Lake properties that was greater than the ones that occurred on lakefront properties at Lake Beulah or the Lauderdale Lakes. To address such issues, we first use a binary (0-1) indicator variable denoting whether a home has lakefront and interact this variable with both a community (location) indicator variable and a time (year) indicator variable. Next, we utilize a variable denoting the linear feet of lakefront on a particular lake and interact it with time (year) indicator variables. Finally, we add a measure of water quality to the models. Specifically, we employ available data on time trends in secchi depth readings at each of the three lakes. Secchi depth is the standard for measuring water clarity.

A number of other traditional explanatory variables are typically found to influence residential property values, and we include such variables in our models. We employ specifications that are generally similar to those used by Brown and Pollakowski (1977) 
and Palmquist (1984) and so include variables such as number of bedrooms, number of bathrooms, square feet of living space, the size of an attached garage, the existence of a basement, the existence of central air conditioning, and the existence of a natural fireplace. In addition to shoreline length used in Boyce and Taylor (2001), we include the square of shoreline feet to control for diminishing marginal benefit of shoreline. While the coefficient on shoreline feet should be positive, the coefficient of shoreline feet squared is expected to be negative, indicating a decreasing marginal benefit. The specific hedonic models estimated in this article are outlined in the following section.

\subsection{Specific Hedonic Equations}

The goal of our analyses is to calculate the degree to which the value of real estate on Delavan Lake was affected by the improvement in lake quality resulting from the lake rehabilitation project. Table 1 provides definitions and summary statistics for the variables used in the analysis. A series of regressions was estimated in which the dependent variable was the assessed value of a property's land and improvements (i.e., land plus dwelling). Three regression models were estimated. There are factors in common across all three models, but each has a somewhat different objective. In the first model, the presence/absence of lakefront interacted with time indicator variables for each observation serve as the key independent variables. This model is represented by the following equation:

$$
V_{i t}=\alpha+\Sigma \beta_{i t}\left(\text { Time }_{i t} \mathrm{XShorelineD_{it }}\right)+\delta\left(X_{i t}\right)+\Sigma \phi_{t}\left(\text { Time }_{t}\right)+\varepsilon_{i t}
$$

where Time $_{i t} \mathrm{xShoreline \textrm {D } _ { i t }}$ is a series of interaction terms between the time indicator variables and either the Delavan Lake shoreline binary indicator variable or the comparison lake's shoreline binary indicator variable; $X_{i t}$ is a vector that includes the housing characteristics mentioned above; and Time ${ }_{t}$ represents the time indicator variables. ${ }^{6}$ Recall that the three time periods (years) included in the analysis are 1987, 1995, and 2003. A primary objective of this first model in (1) is to provide a simple and clear estimate of the increment to property value that occurs when a house is located on the shore of a given lake and to examine the way in which that value increment has varied over time. We pay particular attention to the difference in value increments before and after the rehabilitation of Delavan Lake.

The second model alters equation (1) by including shoreline feet interacted with time indicator variables as the key explanatory variables (zero feet is recorded for non-lake housing) in place of the simple binary indicator variable for shoreline:

$$
V_{i t}=\alpha+\Sigma \beta_{i t}\left(\text { Time }_{i t} \mathrm{XShoreline}{ }_{i t}\right)+\delta\left(X_{i t}\right)+\Sigma \phi_{t}\left(\text { Time }_{t}\right)+\varepsilon_{i t},
$$

where Time $_{i t} \mathrm{x}$ Shoreline ${ }_{i t}$ is a series of interaction terms between the time indicator variables and either the Delavan Lake shoreline linear feet variable or the comparison

${ }^{6}$ The 1987 time indicator variable is omitted to avoid perfect multicolinearity. 
TABLE 1

Summary Statistics

\begin{tabular}{lccc}
\hline Variable & Observations & Mean & Std. Dev. \\
\hline Real Land Value (\$) & 938 & 93,293 & 123,509 \\
Real Total Property Value (\$) & 938 & 184,892 & 196,252 \\
Lakefront (feet)* & 942 & 52 & 83 \\
Basement (square feet) & 939 & 810 & 706 \\
Natural Fireplace (1 if yes) & 942 & 0.36 & 0.52 \\
Attached Garage (square feet) & 939 & 161 & 275 \\
Central Air Conditioning (1 if yes) & 942 & 0.45 & 0.5 \\
Full Bath (number) & 942 & 1.6 & 0.9 \\
Half Bath (number) & 939 & 0.33 & 0.5 \\
Bedroom (number) & 942 & 3 & 1 \\
Living Area (square feet) & 939 & 1,702 & 1,061 \\
\hline * The actual mean footage for shoreline property is about 105 feet. The value presented here is \\
smaller because non-lakefront properties are included in the sample. \\
\hline \multicolumn{4}{l}{} \\
\hline
\end{tabular}

lake's shoreline linear feet variable; $X_{i t}$ is a vector that includes the housing characteristics mentioned above; and $\mathrm{Time}_{t}$ represents the time indicator variables. A primary objective of model (2) is to estimate the dollar value over time of a foot of lake shoreline on Delavan Lake relative to the comparison lakes (the contribution of shoreline to the value of properties, ceteris paribus).

For the third model, we include measures of water clarity (secchi depth readings) taken at each of the three study lakes in each of the three years included in the analysis. These secchi depth data are presented in the results section of this article. In addition to the water clarity variable, we include time indicator variables (as in Eqns. (1) and (2)) and also lake community indicator variables identical to those embedded in the shoreline dummy interaction terms in (1). We include these indicators in order to estimate a model that is as parallel to (1) and (2) as possible while also including a measure of water clarity. The model is:

$$
V_{i t}=\alpha+\Sigma \beta_{i}\left(\text { Shorecommunity }_{i}\right)+\delta\left(X_{i t}\right)+\Sigma \phi_{t}\left(\text { Time }_{t}\right)+\gamma\left(W Q_{i t}\right)+\varepsilon_{i t}
$$

where Shorecommunity $D_{i}$ is a binary $(0-1)$ indicator variable denoting whether a dwelling is located in shore community $i$ ( $i=$ Lauderdale shorefront, Delavan shorefront, Beulah shorefront), with the omitted indicator variable being non-shore properties; $W Q_{i t}$ is the secchi depth (water quality) reading at lake $i$ in period $t$; and all other variables are as previously defined. A primary objective of the model in (3) is to estimate the dollar value of a one-foot change in lake water clarity, holding other factors constant.

Finally, given that the LM heteroskedasticity test indicates heteroskedastic variance of the error term, we use a procedure proposed by White (1980) to generate heteroskedasticity-consistent estimates. 


\section{MODEL RESULTS}

\subsection{Hedonic Results for Presence/Absence of Lakefront}

The estimation results of the hedonic regression based on equation (1) are presented in Table 2. By and large, the coefficients have the expected signs and magnitudes. The coefficients on the housing characteristic variables all have the anticipated sign: basement size, living space, number of bathrooms, and the size of an attached garage are all positive and significant. ${ }^{7}$ In addition, the time indicator variables are also positive, indicating the general appreciation of property over time. In reference to the hypothesis of the restoration event, the relative increase in the value of lakefront on Delavan Lake between 1987 and 1995 is apparent. Controlling for other factors and the general increase in all property values, the value of lakefront on Delavan Lake increased from $\$ 57,587$ in 1987 to $\$ 261,406$ in 1995 - a 354 percent increase. During the same period, the value of lakefront on Lake Beulah and the Lauderdale Lakes (Other Lakes) increased in value by 222 percent. Other than the restoration project, it is difficult to imagine why Delavan Lake properties appreciated so much more than the other lake properties. However, once the benefit of the restoration project was fully capitalized into the value of property, the appreciation attributable to lakefront slowed: between 1995 and 2003, Lauderdale and Beulah properties appreciated 57 percent, while Delavan properties appreciated just 22 percent.

\subsection{Hedonic Results for Linear Feet of Lakefront}

The estimation results of the hedonic regressions based on equation (2) are given in Table 3. The results show that the appreciation of lakefront on Delavan Lake between 1987 and 1995 exceeded the appreciation of lakefront on the other two Walworth County lakes. Lakefront at Delavan Lake was valued at $\$ 665$ per foot in 1987 , as compared to $\$ 539$ per foot for the lakeshore properties on Lake Beulah and the Lauderdale Lakes. The Delavan Lake restoration between 1987 and 1995 increased the value of the shoreline by 352 percent (to $\$ 3,010$ in inflation-adjusted dollars). The other two lakes saw a rise in average property value of 282 percent (from $\$ 539$ to $\$ 2,060$ ).

However, as in Equation (1), this advantage accrued by Delavan in the early 1990s did not continue. The value of shoreline from 1995 to 2003 increased on Delavan by only 10 percent, while it appreciated by 54 percent on the other two lakes. The control variables in this regression again produced the anticipated results.

Finally, there is limited evidence that shoreline exhibits decreasing marginal valuation. This is reflected in the coefficient on the square of shoreline appearing as negative and significant in 1995 and 2003 for Lake Beulah and the Lauderdale Lakes.

\footnotetext{
${ }^{7}$ We note that number of bedrooms is not a significant determinant of residential valuation. Given that we include square footage as a variable, it is not surprising that the bedroom variable is insignificant, possibly because as more bedrooms are added while holding square footage constant, the average size of the bedroom would fall.
} 
TABLE 2

Hedonic Equation (1): Value of Land Plus Dwelling Regressed on Shoreline Binary Indicator Times Year Interaction Terms and Other Variables

Regression Results with correction for heteroskedasticity-consistent standard errors. Dependent variable is the combined value of land plus improvements (dwelling).

\begin{tabular}{|c|c|c|}
\hline Variable & Coefficient & $\underline{\mathrm{t} \text {-statistic }}$ \\
\hline Intercept & $-\$ 13,237$ & -0.69 \\
\hline Time1995 & $\$ 15,425$ & $2.26 * *$ \\
\hline Time2003 & $\$ 36,474$ & $6.03 * * *$ \\
\hline Delavan Lake ShorelineDxTime1987 & $\$ 57,587$ & $2.82 * * *$ \\
\hline Other Lakes ShorelineDxTime1987 & $\$ 59,819$ & $4.57 * * *$ \\
\hline Delavan Lake ShorelineDxTime1995 & $\$ 261,406$ & $8.23 * * *$ \\
\hline Other Lakes ShorelineDxTime1995 & $\$ 192,504$ & $13.03^{* * *}$ \\
\hline Delavan Lake ShorelineDxTime2003 & $\$ 318,566$ & $6.38 * * *$ \\
\hline Other Lakes ShorelineDxTime2003 & $\$ 301,782$ & $15.56^{* * *}$ \\
\hline Basement Square Feet & $\$ 47$ & $5.38 * * *$ \\
\hline Natural Fireplace (1 if yes) & $\$ 10,771$ & 1.29 \\
\hline Attached Garage Square Feet & $\$ 65$ & $3.49 * * *$ \\
\hline Central Air ( 1 if yes) & $-\$ 11,684$ & -1.46 \\
\hline Number of Bathrooms & $\$ 22,459$ & $3.04 * * *$ \\
\hline Number of Bedrooms & $-\$ 2,792$ & -0.42 \\
\hline Living Area Square Feet & $\$ 37$ & $3.10^{* * *}$ \\
\hline \multicolumn{3}{|l|}{ Adjusted $\mathrm{R}^{2}=0.695$} \\
\hline
\end{tabular}

Somewhat surprisingly, the coefficient on the square of shoreline is not significant for Delavan Lake.

\subsection{Inclusion of Water Quality Indicator in the Hedonic Model}

In the results presented above, we use an "event history" approach to ascertain the potential impacts of the lake restoration on property values. Alternatively, we also present an estimate of the impact of lake restoration using a measure of lake water quality. Specifically, we obtained information from the State of Wisconsin Department of Natural Resources and from the Lauderdale Lakes Management District on secchi depth readings, a measure of water quality based on visibility. Table 4 presents the secchi depth readings for the three lakes. Generally, there has been an upward trend in water clarity, which may be due in part to overall improvements in lake management. Delavan Lake, however, experienced a significant jump in water clarity between 1987 and 1995 and a modest decline between 1995 and 2003.

The water quality hedonic regression includes secchi depth as a measure of water quality but also is constructed to be as parallel as possible in structure to the "event history" hedonic regressions presented above. Specifically, the regression includes both 
The Review of Regional Studies, Vol. 36, No. 2, 2006, pp. 221-238

\section{TABLE 3}

Hedonic Equation (2): Value of Land Plus Dwelling Regressed on Shoreline Length Times Year Interaction Terms and Other Variables

\begin{tabular}{|c|c|c|}
\hline \multicolumn{3}{|c|}{$\begin{array}{l}\text { Regression Results with correction for heteroskedasticity-consistent standard errors. } \\
\text { Dependent variable is the combined value of land plus improvements (dwelling). }\end{array}$} \\
\hline Variable & Coefficient & t-statistic \\
\hline$\overline{\text { Intercept }}$ & $\$ 50,933$ & $3.10^{* * *}$ \\
\hline Time1995 & $\$ 17,264$ & $2.52 * *$ \\
\hline Time2003 & $\$ 45,811$ & $5.94 * * *$ \\
\hline Delavan Lake Shoreline Length x Time1987 & $\$ 665$ & 1.14 \\
\hline (Delavan Lake Shoreline Length x Time1987) & $-\$ 0.12$ & -0.03 \\
\hline Other Lakes Shoreline Length x Time1987 & $\$ 539$ & $3.14^{* * *}$ \\
\hline (Other Lakes Shoreline Length x Time1987) $^{2}$ & $-\$ 0.34$ & -1.12 \\
\hline Delavan Lake Shoreline Length x Time1995 & $\$ 3,010$ & $2.79^{* * *}$ \\
\hline (Delavan Lake Shoreline Length x Time1995) & $-\$ 2.86$ & -0.28 \\
\hline Other Lakes Shoreline Length x Time1995 & $\$ 2,060$ & $11.89 * * *$ \\
\hline (Other Lakes Shoreline Length x Time1995) ${ }^{2}$ & $-\$ 2.09$ & $-5.30 * * *$ \\
\hline Delavan Lake Shoreline Length x Time2003 & $\$ 3,325$ & $1.73^{*}$ \\
\hline (Delavan Lake Shoreline Length x Time2003) & $-\$ 1.05$ & -0.06 \\
\hline Other Lakes Shoreline Length x Time2003 & $\$ 3,179$ & $10.22 * * *$ \\
\hline$\left(\right.$ Other Lakes Shoreline Length x Time2003) ${ }^{2}$ & $-\$ 3.56$ & $-4.09 * * *$ \\
\hline Basement Square Feet & $\$ 28$ & $5.38^{* * *}$ \\
\hline Natural Fireplace (1 if yes) & $\$ 15,182$ & $1.65^{*}$ \\
\hline Attached Garage Square Feet & $\$ 47$ & $2.85 * * *$ \\
\hline Central Air ( 1 if yes $)$ & $-\$ 10,069$ & -1.33 \\
\hline Number of Bathrooms & $\$ 21,077$ & $3.21^{* * *}$ \\
\hline Number of Bedrooms & $-\$ 4,794$ & -0.92 \\
\hline Living Area Square Feet & $\$ 28$ & $2.82 * * *$ \\
\hline \multicolumn{3}{|l|}{ Adjusted $\mathrm{R}^{2}=0.756$} \\
\hline
\end{tabular}

year indicator variables (Time1995 and Time2003) and community indicator variables (for Lauderdale, Delavan, and Beulah) in addition to the secchi depth variable (Waterclar). Aside from other reasons, the importance of including these two suites of indicator variables, in similar fashion to the approach used in the event history regressions, is indicated by inspection of the secchi depth data in Table 4. First, the general increase in water clarity over time is likely to be partially correlated with general increases in property values over time attributable to a number of non-measurable factors.

Thus the inclusion of the year indicator variables is important. Second, notice that there are substantial differences in water clarity among the three lakes studied. At the same time, there are a host of non-measurable but potentially important community effects that may influence property values. Therefore it is important to include community-specific indicator variables in order to better disentangle the effects of water 
TABLE 4

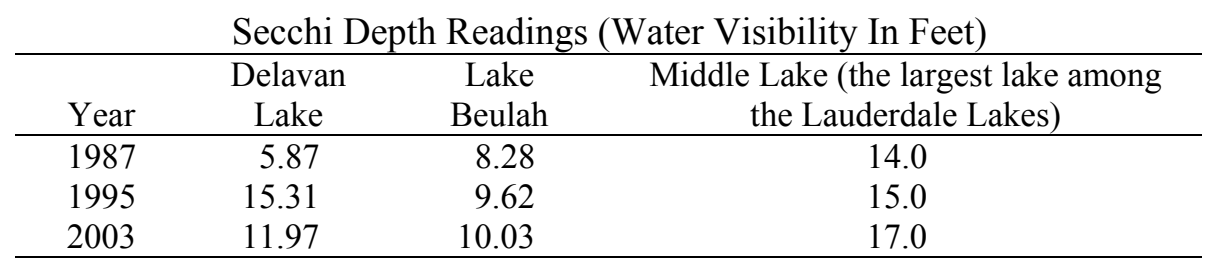

quality on property values from the effects of tangible but hard-to-measure differences in community fabric across the three areas. ${ }^{8}$

Table 5 shows the results of the water quality indicator hedonic regression. In general, the estimated coefficients and statistical significance levels of the control variables are broadly similar to the results of the event history hedonic regressions shown above. Basement square footage, number of full baths, and living area square footage all contribute positively to property value at the 1 percent level of statistical significance. The presence of a natural fireplace is also statistically significant at the 1 percent level. While the estimated coefficient of the fireplace variable $(\$ 50,624)$ is perhaps substantially larger than one might expect, we surmise that for the stock of homes in the sample the presence of a fireplace is highly correlated with several other unmeasured factors that add to the value of a house (e.g., hardwood floors, custom kitchen features, custom lighting fixtures, etc.).

The estimated coefficients for the time and community indicator variables are also in accordance with expectations. After controlling for the property-specific and lake quality variables included in the model, the general rise in property values over time is apparent by inspection of the results for Time1995 and Time2003. The average property was worth about $\$ 70,000$ more in 1995 than in 1987, and about $\$ 140,000$ more in 2003 than in 1987, ceteris paribus (level of significance $=1$ percent). The estimated coefficients on the community effects indicator variables illustrate the average premiums commanded by homes by virtue of their location in particular communities, ceteris paribus.

Finally, the regression in Table 5 also shows that the variable of primary interest (Waterclar) has a positive coefficient that is statistically significant at the 5 percent level. The value of this coefficient indicates that for every one foot increase in water clarity, on average, lake property values increased by $\$ 5,207$ after controlling for the other variables in the model. Thus, between 1987 and 1995 the average Delavan Lake property experienced an increase of about $\$ 49,000$ attributable to lake restoration. In contrast, Lake Beulah and Lauderdale Lakes experienced about a one-foot increase in clarity and thus an approximate $\$ 5,000$ increase in valuation per house attributable to changes in water clarity. Note again that these point estimates for the value of water clarity are derived

${ }^{8} \mathrm{We}$ note that even with time and lake fixed effects it is still possible that some omitted characteristics are correlated with water quality. Thus, the coefficient for water quality may be biased upward because of the potential correlation with other quality improvements over time. 
The Review of Regional Studies, Vol. 36, No. 2, 2006, pp. 221-238

\section{TABLE 5}

Hedonic Equation (3): Value of Land Plus Dwelling Regressed on Lake Water Clarity and Other Variables

\begin{tabular}{|c|c|c|}
\hline \multicolumn{3}{|c|}{$\begin{array}{l}\text { Regression Results with correction for heteroskedasticity-consistent standard errors. } \\
\text { Dependent variable is the combined value of land plus improvements (dwelling). }\end{array}$} \\
\hline Variable & Coefficient & t-statistic \\
\hline Intercept & $-\$ 173,583$ & $-4.81 * * *$ \\
\hline Waterclar & $\$ 5,207$ & $2.34 * *$ \\
\hline Time1995 & $\$ 70,526$ & $6.54 * * *$ \\
\hline Time2003 & $\$ 140,059$ & $11.12 * * *$ \\
\hline Delavan Lake Community Indicator & $\$ 50,123$ & $2.93 * * *$ \\
\hline Lauderdale Lakes Community Indicator & $\$ 20,657$ & 0.56 \\
\hline Lake Buelah Community Indicator & $\$ 205,714$ & $10.46 * * *$ \\
\hline Basement Square Feet & $\$ 51$ & $5.09 * * *$ \\
\hline Natural Fireplace (1 if yes) & $\$ 50,624$ & $4.98 * * *$ \\
\hline Attached Garage Square Feet & $-\$ 15$ & -0.71 \\
\hline Central Air ( 1 if yes) & $-\$ 4,726$ & -0.52 \\
\hline Number of Bathrooms & $\$ 42,227$ & $4.27 * * *$ \\
\hline Number of Bedrooms & $-\$ 2,887$ & -0.39 \\
\hline Living Area Square Feet & $\$ 48$ & $4.02 * * *$ \\
\hline \multicolumn{3}{|l|}{ Adjusted $\mathrm{R}^{2}=0.602$} \\
\hline
\end{tabular}

after controlling for unobserved factors of influence across the three communities and three time periods of analysis.

\subsection{Comparison of the Hedonic Results for Value of Water Clarity}

It is useful to compare directly the results of hedonic equations (1) and (3) (Tables 2 and 5, respectively) in terms of the value of an additional foot of water clarity at Delavan Lake. Inspection of Table 2 shows that the average increase in value from 1987 to 1995 of a property with Delavan Lake shoreline was $\$ 203,819$ (=\$261,406 - \$57,587). Given that there was an increase in water clarity (secchi depth) of 9.44 feet at Delavan Lake over this time period (Table 4), this implies that the increase in the value of a Delavan lakeshore property per foot of improvement in clarity was approximately $\$ 21,600$. Note that this is considerably larger than the estimate of $\$ 5,207$ per foot of clarity that was yielded by the hedonic equation (3) (Table 5).

Comparison of the results from Equations (1) and (3) illustrates the insight yielded by including an explicit measure of water quality as a regressor in addition to a) time indicator variables that "bracket" the cleanup event and b) community indicator variables that allow for differential and unmeasured community effects on property values. At the same time, it is not necessarily valid to assume that the water clarity coefficient from Equation (3) yields a more correct point estimate of the value of the Delavan Lake rehabilitation 
than does the event history approach in Equation (1). This is because the Delavan Lake rehabilitation led to an improvement in a larger bundle of lake attributes than solely water clarity. Such attributes include the quality of the recreational fishing experience (game species present, average fish size, expected catch rate, etc.), concentrations of non-point source pollutants, lake odor, and so on. As a result, the larger suite of improvements in attributes produced by the rehabilitation project may be reflected in Equation (1) by the estimated coefficients of not only the water clarity variable, but also the time indicator variables. It is not feasible to determine the ways in which the impacts of the total suite of improvements are split among these various coefficients.

Due to the above considerations, it is reasonable to postulate that the estimated coefficient for the water clarity variable in (3) $(\$ 5,207$ per foot of improvement in clarity) indicates a "lower" estimate for the range of true property value benefits of the lake rehabilitation project. In the same way, it is reasonable to view the estimate resulting from the event history approach in (1) (\$21,600 per foot of improvement in clarity) as a "higher" estimate of the property value benefits. In the next section, we conclude by discussing briefly the implications of the results for property values and taxes in the Delavan Lake community.

It is also important to recognize that property other than lakeshore property is likely positively affected by the rehabilitation event. For example, non-riparian properties with private lake access may have experienced an increase in property values. Similarly, other nearby non-riparian properties may have also increased in value simply because of close proximity and accessibility of the lake via the public access points. Commercial properties may also have increased in value as a result of the rehabilitation. Thus, our analysis measures one of several components of the economic impact of the lake rehabilitation and therefore does not necessarily reflect the total impact of the lake rehabilitation to the community.

\section{CONCLUSIONS}

This research uses hedonic analysis to evaluate the effect of the Delavan Lake restoration project on property values. Our analysis shows that this event produced financial benefits to the homeowners in the years following the lake restoration. Shoreline properties located on Lake Beulah and the Lauderdale Lakes appreciated by 148 percent between 1987 and 2003. Our analysis demonstrates that the above market returns on Delavan Lake properties are attributable to the lake restoration project. ${ }^{9}$ Without it, this analysis suggests that forces would have led to a market appreciation of 148 percent

\footnotetext{
${ }^{9} \mathrm{We}$ acknowledge that it is possible that some other factor is causing the relatively higher increase in Delavan Lake property valuation over the 1987-1995 period. However, discussions with residents and real estate agents familiar with the Delavan market did not reveal other possible causes.
} 
instead of the actual 273 percent appreciation. ${ }^{10}$ In that event, shoreline lots on Delavan Lake would have appreciated from $\$ 78,848$ to $\$ 117,367$ rather than the actual appreciation to $\$ 294,185$. As a result, there was a windfall return of $\$ 176,818$ for the owner of an average Delavan Lake property. In 2004, there were 565 homes with shoreline on Delavan Lake. This translates into an aggregate increase in valuation of over $\$ 99$ million. This is a contribution to the real wealth of Walworth County, Wisconsin, and it is important to note that this also results in a redistribution of property tax burden within the community.

In 2003, the equalized value of all property in the town of Delavan was $\$ 702$ million, which generated $\$ 1,843,273$ in township property tax revenues. Assuming that the township operates efficiently and there are no areas in which to trim the budget, in the absence of the $\$ 99$ million increase in valuation attributable to lake restoration, property tax rates would have been higher than they are. In this hypothetical scenario, the off-lake properties experience a reduction in property taxes of 14 percent. Of course, this effect repeats itself at the county and school district levels. ${ }^{11}$ In aggregate, the estimated mil rate applied to an "off-lake" property in the town of Delavan would have been $\$ 0.89$ higher had the restoration project not occurred, which for a $\$ 200,000$ home generates a tax saving of $\$ 178 .^{12}$

As with any empirical analysis, hedonic studies are vulnerable to the potential for omitted variable bias. However, there is a theoretical link between property values and changing environmental amenities. Together, the theory and empirical evidence constitute a prima facie case for the hypothesis that changing lake water quality influenced shoreline values on Delavan Lake. In this study, the lake rehabilitation event at Delavan Lake caused a substantial increase in water quality that appears to have resulted in a significant increase in shoreline property values. This conclusion is robust in the sense that it continues to hold after controlling for unmeasured, underlying factors that vary across both time and the communities studied.

Most of the funding of the lake rehabilitation was provided by federal and state grants. While the community as a whole clearly benefited from the rehabilitation event, our results show that in fact the primary beneficiaries were the lakeshore property owners. One could therefore argue that the property owners ought to have shared in funding the cost of the project in proportion to their benefits. The Delavan Lake Sanitary

\footnotetext{
${ }^{10}$ In the numerical illustration that follows, we use the property value impact estimate derived from this article's event history approach (Eqation (1)). Use of the lower estimate derived from the water clarity equation (3) would change (lower) the results of the numerical illustration but would not alter the general findings.

${ }^{11}$ Conceptually, we could also make similar calculations for the Delavan Lake Sanitary District. However, since the sanitary district primarily services residents on and around Delavan Lake, it seemed inappropriate to include it in this portion of the analysis.

${ }^{12}$ This analysis excludes any reduction in the State of Wisconsin and the Vocation Technical College portion of the property tax, although it is notable that if portions were to be included, the tax saving estimate would be slightly higher.
} 
District could feasibly have accomplished this by imposing a special assessment on lakeshore property owners to recover project expenditures. However, one challenge is identifying what proportion of the project cost ought to have been funded by those who received a direct benefit. Identifying this proportion is further complicated by the uncertainty of the outcome: at the time of project implementation, it was unclear as to whether the lake rehabilitation effort would be successful.

Finally, although the evidence presented in this article indicates that the rehabilitation event had significant positive economic effects for the Delavan community, it does not follow that a similar rehabilitation effort on another lake would necessarily result in the same outcome. In our assessment three critical components must be present in order for other lake communities considering a lake rehabilitation investment to experience a similar outcome: 1) the lake must have experienced significant degradation; 2) the rehabilitation event must result in observable improvements in water quality; and 3) there must be the presence of potential buyers within the community or nearby market (i.e., Chicagoland).

\section{REFERENCES}

Birch, J.W. and M.A. Sunderman, 2003. "Estimating Price Paths for Residential Real Estate," Journal of Real Estate Research 25(3), 277-300.

Boyce, K.J. and L.O. Taylor, 2001. "Does the Measurement of Property and Structural Characteristics Affect Estimated Implicit Prices for Environmental Amenities in a Hedonic Model? Journal of Real Estate Finance and Economics 22(2/3), 303-318.

Boyle, K.J., S.R. Lawson, H.J. Michael, and R. Bouchard, 1998. "Lakefront Property Owners' Economic Demand for Water Clarity in Maine Lakes," Maine Agriculture and Forest Experiment Station Miscellaneous Report 410, University of Maine.

Brashares, E.N., 1985. "Estimating the Instream Value of Lake Quality in Southeast Michigan," Dissertation, University of Michigan.

Brown, G. and H. Pollakowski, 1977. "Economic Value of Shoreline," The Review of Economics and Statistics 59(3), 231-249.

Clapp, J. and C. Giaccotto, 1992. "Estimating Price Indices for Residential Property: A Comparison of Repeat Sales and Assessed Value Methods," Journal of the American Statistical Association 87 (418), 300-306.

Darling, A., 1973. "Measuring Benefits Generated by Urban Water Parks," Land Economics 49(1), 22-34.

David, E.L., 1968. "Lakeshore Property Values: A Guide to Public Investment in Recreation," Water Resources Research 4(4), 697-707.

Eiswerth, M.E., R. Kashian, and M. Skidmore, 2005. "What is the Value of a Clean and Healthy Lake to a Local Community?" Prepared for Delavan Lake Improvement Association and University of Wisconsin - Extension. Final report, February 2005. Whitewater, WI: Fiscal and Economic Research Center, University of WisconsinWhitewater. 
Epp, D. and K.S. Al-Ani, 1979. "The Effect of Water Quality on Rural Non-Farm Residential Property Values," American Journal of Agricultural Economics 61, 529534.

Leggett, C.G. and N.E. Bockstael, 2000. "Evidence of the Effects of Water Quality on Residential Land Prices," Journal of Environmental Economics and Management 39, 121-144.

Mendelsohn, R., D. Hellerstein, M. Huguenin, R. Unsworth, and R. Brazee, 1992. "Measuring Hazardous Waste Damages with Panel Models," Journal of Environmental Economics and Management 22, 259-271.

Michael, H.J., K.J. Boyle, and R. Bouchard, 1996. "Water Quality Affects Property Prices: A Case Study of Selected Maine Lakes," Maine Agriculture and Forest Experiment Station Miscellaneous Report 398, University of Maine. , 2000. "Does the Measurement of Environmental Quality Affect Implicit Prices Estimated from Hedonic Models?" Land Economics 76 (2), 283-298.

Palmquist, R.B., 1984. "Estimating the Demand for the Characteristics of Housing," The Review of Economics and Statistics 66 (3), 394-404.

Plattner, R. and T. Campbell, 1978. "A Study of the Effect of Water View on Site Value," The Appraisal Journal 46(1), 20-25.

Pollakowski, H.O., 1995. "Data Sources for Measuring Housing Price Changes," Journal of Housing Research 6(3), 377-387.

Poor, P.J., K.J. Boyle, L.O. Taylor, and R. Bouchard, 2001. "Objective versus Subjective Measures of Water Clarity in Hedonic Property Value Models," Land Economics 77(4), 482-493.

Rosen, S., 1974. "Hedonic Prices and Implicit Markets: Product Differentiation in Pure Competition," Journal of Political Economy 82, 34-55.

Seiler, M.J., M.T. Bond, and V.L. Seiler, 2001. "The Impact of World Class Great Lakes Water Views on Residential Property Values," The Appraisal Journal 69, 287-295.

Steinnes, D., 1992. "Measuring the Economic Value of Water Clarity: The Case of Lakeshore Land," Annals of Regional Science 26, 171-176.

White, H., 1980. "A Heteroskedasticity-Consistent Covariance Matrix Estimator and a Direct Test for Heteroscedasticity," Econometrica 48, 817-838.

Young, C.E. and F.A. Teti, 1984. "The Influence of Water Quality on the Value of Recreational Properties Adjacent to St. Albans Bay. U.S. Department of Agriculture: Economics Research Service, Natural Resource Economics Division. 